\title{
The role of geoscientists in human progress
}

\author{
Stefania Lucchesi, Marco Giardino ${ }^{\star}$
}

Università degli Studi di Torino, Dipartimento di Scienze della Terra, Torino, Italy

\author{
Article history \\ Received December 21, 2011; accepted March 27, 2012 \\ Subject classification: \\ Geoethics, Environment, Sustainability, Scientific communication.
}

\begin{abstract}
Like any science, geology has a key role in the development and progress of human culture and society. In this context, scientists, professionals and practitioners of Earth sciences must inevitably confront themselves with the purposes, methods and results of their studies, concerning relationships between man and his environment, which thus deals with ethical questions. An essential base for any geo-environmental action should be respect for the natural ecosystem. This can be achieved by encouraging an 'affectionate attitude' towards Nature or ecology. Some ancient cultures had a great awareness of the close relationships between humankind and the Earth. The recent web-based Museo Torino (Turin Museum) multimedia product shows the 'history of a city' (Turin, Italy) in a dimension of unity and as a continuum of space-time-life between the history of the Earth and of humans. Geoscientists are not limited to merely having a pragmatic vision of the Earth, but should pursue harmonious collaboration between man and Nature. Within complex Earth systems, scientists and professionals rediscover their geoethical roles by responsibly evaluating and managing georesources, for progress aimed at improving conditions of life and human dignity. Geoscientists can also promote respect for 'human rights' through appropriate educational and training actions, for the balanced exploitation of our georesources. An example from Mendoza (Argentina) is presented here, to encourage opportunities for meetings on environmental issues among people of different backgrounds and cultures. Last, but not least, there is the ethical role of geoscientists in 'the service of the truth'. A misleading view of Earth systems by geoscientists can lead to fatalism or myths that often affect people from the psychological and sociological points of view.
\end{abstract}

\section{Introduction}

Geoethics is a new discipline that involves scientific, technological, methodological and social-cultural aspects of Earth sciences and ethics. It represents the meeting of humanistic disciplines, such as philosophy, epistemology, sociology and ethics, and scientific disiplines, such as geology, natural sciences and ecology. Geoethics can be also considered as part of environmental ethics, as it originates from man's inevitable question about the place he occupies in Nature, about the thoughts and motivations that animate him in his everyday life when dealing with the en- vironment where he lives. After its beginning as philosophical reflection by several geoscientists worldwide, such as Felice Ippolito in Italy in the late 1960s, and its later developments by Vaclav Nemec in 1991, geoethics has now been widely accepted by both Earth and social scientists because of the need for appropriate protocols, scientific integrity issues, and a code of good practice regarding the study of the abiotic world. We can consider geoethics as a largely articulated discipline, dealing, for example, with environmental conservation, georesources prospecting and exploitation, ecosystem protection, geo-research and geosciences education, risk management and mitigation of geohazards, and promotion of geodiversity.

In this report, we want to underline how geoethics is the pulsing heart that provides nutrients to several branches of Earth sciences and their related applications, and we analyze some of the relevant roles that geoscientists can have on the life, culture and society of man, with their studies and professional occupation. We also want to investigate if and how geoethics, in its transversal and multidisciplinary meaning, can have important effects also at a practical level: should geoethics define reference criteria for human behavior both on personal and socio-political grounds? Our preferred scenario is that geoethics has a fundamental role in defining the 'balanced' environmental policies of the future, including sustainable development and adaptation to climate change.

\section{The role of geoscientists in human progress}

Nowadays, the general meaning of 'ethical scientific behavior' appears to be confined to the observance of some international laws and decisions. In the case of Earth scientists and professionals, they are required to respect certain principles deemed as fundamentals by the scientific community and by international policy, such as the principles of subsidiarity [Treaty of Maastricht, European Community 1992], of precaution [United Nations Conference on Environment and Development, United Nations 1992] and of responsibility [Jonas 1990]. 
In this respect, we emphasize the need to consider as fundamental steps in the path of geoethical behavior those that stress the welfare of society. The starting point and the point of arrival of this path should be man: by carefully considering human identity and needs, our society can reach a new awareness of problems that are related to physical and biological environments. If there is no such centrality of the respect for human life, environmental ethics and geoethics are at risk of being manipulated by ideological and political issues, rather than offering an authentic proclamation of truth.

This 'anthropocentric' analytical perspective is in agreement also with the Italian law that recognizes the centrality and importance of man in defining society's quality of life within a given environment: "The environment is protected as a determinative factor in the quality of life. Its protection is not pursued for theoretical or naturalistic aesthetic purposes, but it expresses the present need for a habitat where man lives and acts, and it is necessary for... citizens" [Constitutional Court of the Italian Republic 1987].

It follows that there is a close connection between freedom and responsibility. Also in the case of Earth sciences and geo-environmental applications, responsible management of freedom means making the commitment to work according to general and common rules. This has to be accomplished by all of the people defining, guiding, formalizing and practicing a certain way of acting in the geo-environment.

\section{Basic principles for geoethics applications}

At the base of each project of studying, safeguarding or exploiting the geological environment, we consider it is essential to follow some attitudes or basic principles to give a geoethical meaning to any operational choice in this context. These include the following:

a) It is necessary to stimulate an 'affectionate attitude' towards Nature, and hence to enhance an attitude of taking care of Nature. We believe that it is fundamental to educate, especially the younger generations, to pay better attention to Earth sciences, and not only through the enhancement of their cognitive and practical content, but also by stimulating their sensational and emotional dimensions. These objectives can be taken into account by using practical and interactive methodologies in educational programs, either involving school children or the general public. Several recent applications of such a new educational approach confirm that the first steps for inspiring interest in a scientific topic are to rediscover the ability to be amazed by its contents.

b) Another essential base for geoethics approaches to environmental actions is the enhancement of the order, beauty and harmony inherent in the Earth systems, and in general in Nature. As Earth scientists experience in their everyday research activities (e.g. analyzing crystals, glacial landscapes, sedimentary structures), the Earth and the universe follow 'laws', and their forms are an expression of the orderly system of the Kosmos (= order), even if elements can show different levels of complexity. In this context, the role of geoscientists is fundamental, because their studies can allow people to discover and understand this dimension of the Earth systems, thus considering the possibility of geoheritage evaluation and of a sustainable use of georesources.

c) It should not be forgotten that even if only addressed by some modern tendencies to dominate and exploit $\mathrm{Na}$ ture, the relationships between man and the Kosmos were originally (and still are) characterized by a sort of dependency of man on the Earth. An aid in the understanding of this relationship can be found in some cultures, as generally those native to less economically developed countries than ours. These populations have a greater awareness of the close relationships between humankind and the Earth (e.g. Pachamama-Mother Earth in Latin America, the aborigines of Australia). Although all of these native peoples remind us of ancient and 'subservient' societies, they can also help us to rediscover our original contact point with Mother Nature. A careful consideration of Nature can provide a more balanced approach to georesources, by avoiding over-exploitation of Nature in a wasteful manner, which is typical of an unsustainable but highly luxurious life. Observing the principles of geoethics can lead us to a sober and modest, and sustainable, way of life.

d) At the same time, it is necessary to increase our knowledge, with the 'modern' awareness that we belong to a complex system that is characterized by constant, mutual and inevitable interactions between the Earth and human beings. There are many examples of interactions or symbiotic relationships between biotic and non-biotic elements, from the coral reefs to the human body. As well as interconnections at the physical-chemical-biological level, there are strong interconnections due both to global ecological issues, which include those related to Earth science, and to the present phenomenon of globalization. It is more and more clear that the quality of the Earth system and the management of its resources determine the quality of human life and all living beings as part of one global ecosystem [Praturlon 2004]. The strong interconnections between the major Earth systems (lithosphere, hydrosphere, atmosphere, biosphere) were the starting point for the development during the 1970's of the Gaia hypothesis by Lovelock [1979] and his school, who saw the Earth systems as being part of a single 'living organism'. Beyond this hypothesis, the aim of our geoethical approach sees human beings as interconnected with geo-environments, together with the community of all of the living beings [Hugget 1995]. The planet Earth is our home ground: we have the planet as a common heritage and our vocation should be the balanced management of 
the Earth resources, rather than their unhealthy exploitation and manipulation. This responsibility should be extended in space and time. Indeed, it has to be underlined that every action has consequences in both space and time; this needs to be considered to ensure inter-generation and intra-generation equal opportunities [United Nation 1987].

Following these principles, we carried out our geological research and dissemination experience for the recent Museo Torino project, a web-based and multimedia product of the Turin Municipality for the 150th anniversary of the Unification of Italy. On the website and in the introductory part of the didactic film "Turin, history of a city", we outlined the different stages of the history of its geographical location from 5 million years ago to the near future. Through the representation of what we have called "The City before the City", we have tried to communicate that there is a dimension of unity and a continuum of space-time-life in the geological and human histories.

\section{Different possible roles for geoscientists}

Based on the above-mentioned principles, geoscientists are not limited to conform to a merely pragmatic vision of the Earth with the aim being to only provide technical instruments, to elaborate on scientific advances, or to perform services related to geohazard mitigation, with noble and high social objectives (e.g. in the contributions of geoscientists to civil protection activities). Rather, geoscientists can have several value-added aims that have different ethical implications, as follows:

1) Mankind is the only living species that can give rational sense to its actions, to consciously modify the Earth system. Man can plan and realize plans to govern the geoenvironment, to interact with natural processes, and to change or introduce new equilibria. For these reasons, geoscientists have an important role in the rediscovering of the human role and dignity. Indeed, human beings can safeguard and responsibly manage the assets of their home, the Earth, to improve the conditions of life and to enhance human progress.

A historical perspective reveals that the term geologia appeared for the first time in the early 17 th century in the posthumous work of Ulisse Aldrovandi [1648], and the rise of a systematic geological thought developed only since the second half of the 17th century with the Danish geoscientist Niels Steensen [1669]. Nevertheless, due to their intelligence and knowledge of the Earth processes, human beings have always made determinate, geologically oriented choices in 'building their habitat'. For example, they had to choose where to build cities, where and how to find raw materials, and how to avoid involvement in natural disasters [Panizza 2005].

Nowadays, these fundamental choices should also consider global change, which is a problem that encom- pass the full range of global issues and interactions concerning natural and human-induced changes to the Earth environment. In a global geoethical perspective, we should use both adaptation measures and proactive responses to global change in order not to alter the ability of the Earth to sustain life [Munn 1996].

2) Every geological action should (ideally) be seen as part of a harmonious collaboration between man and Nature, in a relationship of inter-dependence between the biotic and abiotic components, typical of a complex system like our planet Earth.

In this view, any human projects and actions involving the Earth systems should not be considered 'for' or 'towards' the environment but more and more in harmony 'with' the environment! For example, by dealing with the effects of accelerated erosion in different regions through time, man has developed different 'synergic' management techniques, such as hillslope terracing, drainage systems, and replanting. These solutions can protect soils from erosion and landscapes from degradation; at the same time, soil conservation is useful for the development of agriculture. On the other hand, some other agricultural techniques, such as excavation of settling ponds, and seeding and mulching of bare surfaces, can be used themselves to reduce sediment removal [Reed 1980, Hooke 1994].

Morever, landscape 'recovery' is possible from impacts due to exploitation of georesources, as in the case of postmining restoration of geoenvironments. By following a geoethical approach, rather than simple restoration by waste infilling, naturalization processes should be suggested, to return the system to a condition that can be sustained by natural processes [Goudie 2000].

3) Geoscientists are also called on to promote respect for human rights, by providing their knowledge and studies for educational and training actions which affirm the Earth and its resources as a common heritage, to be shared with the community of living beings.

As an example, the case of an international political debate related to the exploitation of a gold mine in San Carlos, Mendoza (Argentina) is analyzed. Here, the use of arsenic for gold extraction compromised the quality of the water resources over a vast urban area. Comprehensive information of a large sector of the population and increased awareness of local administrators, with support from Earth scientists and experts, were fundamental to thwart this dangerous exploitation approach and to favor land conservation together with respect for the human rights in the area.

4) Regarding human rights, in a globalized society, where poor distribution of resources is often the cause of conflict between nations, geoscientists can indirectly become promoters of justice and peace, through correct management and equal distribution of the benefits derived from the georesources. Indeed, these georesources should 
be considered as shared heritage, to serve and benefit all of humanity, including the poorest people.

In terms of oil or other mineral resources having a crucial role from an economic standpoint, it is evident that they often cause international conflict. It can be seen, for example, that near the oil fields and pipelines in the Middle East there is increased concentration of conflict and political vulnerability. Geopolitics in this case can be correctly guided by geoethical principles: by careful analysis and planning of the natural placement of resources and their distribution lines, geoscientists can favor balanced economic and political choices that are as peaceful as possible [Biancotti and Biancotti 2004].

5) Furthermore, as a safeguard for the Earth, the home of all peoples, there is a common target of different cultures: geoscientists can have a significant role in multi-ethnic and multi-cultural dialog, to encourage opportunities to meet on environmental issues with people of different backgrounds and cultures; e.g. concerning the risk management and mitigation of geohazards. The recognition of shared values can become an occasion for encounters between different cultures. This was the case for the adoption of the Hyogo framework for action by the World Conference on Disaster Reduction of the United Nations General Assembly hold in Kobe-Hyogo, Japan, in 2005, and its subsequent endorsement by 168 countries at the General Assembly of the United Nations. From the shared recognition of the crucial role of human actions in reducing the vulnerability of societies to natural hazards and disasters, a series of strategic goals and related activities were initiated worldwide to promote both substantial reductions in loss of life during disasters, and the social, economic and environmental assets of communities and countries [Keller et al. 2008].

6) Last but not least, and also very timely, there is also the role that the geoscientist can have in the service of truth. Indeed, more or less consciously, geoscientists can convey different 'visions of the Earth system' through their scientific communication and/ or popular publications. Different proposals can lead to different ideologies (e.g. catastrophism, fatalism, mythologizing) or simply help to develop a 'common feeling', which can have important effects on public opinion and therefore on human thoughts and behaviors, and on our models for the future. Each prediction and future scenario for climatic change or natural hazards has to deal with conceptual models. Some of these that relate to global warming were synthesized by Maslin [2004].

Today, we are witnessing increasing public attention on issues related to the environment and the changing Earth, although often this does not necessarily correspond to better information. Indeed, misinformation is often more prevalent than correct information. In particular, there are several types of such misinformation that can arise from different causes: ignorance or superstition and fear of the unknown, uncritical acceptance of some unfounded 'pseudo-scientific' claims, incorrect information from groups of people who are interested in giving guidelines to determine specific commercial or political choices. For example, in the early 1990's, an incorrect prediction of a potential earthquake in New Madrid, Missouri, USA, resulted in a state of agitation and anxiety in the local and surrounding population. All the area suffered huge economic damage, fomented also by the national media coverage of the information delivered by climatologist Iben Browning. He predicted in the New Madrid Seismic Zone that there was a $50 \%$ probability of a magnitude 6.5 to 7.5 earthquake in the New Madrid area sometime between December 1 and December 5, 1990. Despite the lack of scientific support, Browning's prediction was widely reported in the international media, which caused public alarm. This event has become a case-study that revealed how important it is to define some important guidelines for communication between scientist and the media:

- Scientists must promptly evaluate any prediction that attracts media coverage.

- The media need to verify their sources of information.

- There should be a coordinated system with an authoritative evaluation of any predictions [Spence et al. 1993].

A correct and honest way of disseminating such information about the Earth system to the public, including both its resources and its hazards, it is very important to gain popular credibility and trust in science. This is the starting point for an educational action that can lead people to follow the correct behavior and lifestyle, and to inspire policy choices for action and prevention. However, society should also be told that despite all of the scientific knowledge and instrumentation nowadays, it is still not possible to predict the exact timing and strength of a potential earthquake, or of volcanic activity, or of a tsunami. A better approach will be to increase public knowledge through education of the following aspects:

- The preparedness of society for dealing with geohazards.

- The efficiency of the warning systems.

- The coordination of post-disaster handling of emergency situations by government agencies and Nongovernmental Organizations.

\section{Conclusions}

From the consciousness of the complexity of the Earth system and of the continuous interactions between the various elements of which it is composed (living beings, or not), it is essential to define the role and responsibility that geoscientists have in this context. It is fundamental to underline that every thought, effort, choice and action within the geoenvironment needs to remain firmly attached to the issue of respect for human life. For this reason the activities 
of Earth scientists cannot ignore the values that are generically known as 'human rights'.

In this context, the work of geoscientists is not merely pragmatic, to perform a service, but rather it should be aimed at promoting sustainable living conditions for each person. Geoscientists have many responsibilities in policy making and in taking care of civil activities. Through education and training activities, geoscientists can develop renewed attention in society towards Nature and the Earth sciences. To enhance the prudent use and management of the Earth resources, geoscientists can contribute to the fostering of North-South inter-governmental cooperation, with particular attention to people in low-income countries.

To summarize these concepts, here we would like to borrow a comment from an important personality of our time, Pope John Paul II, who although not a scientist, believed strongly in the value of science. In his sermon given in Rome in 1983 for the 350th anniversary of the publication of the works of Galileo [1632], he said:

"Ladies and Gentlemen, you who have cultivated the sciences have considerable power and responsibility that might become crucial in the guiding of the world of tomorrow... Your job is noble and huge. The world is watching and expecting from you a service that is worthy of your intellect and your ethical responsibilities".

\section{References}

Aldrovandi, U. (1648). Musaeum metallicum in libros IV distributum, Bologna, typis Io. Baptistae Ferronij.

Biancotti, A., and C. Biancotti (2004). Geopolitica del petrolio. World in progress, Torino, BEM, MS Litografia, $112 \mathrm{pp}$.

Constitutional Court of the Italian Republic (1987). Sentence n. 641, 30 December 1987.

European Community (1992). Treaty on European Union. Provisions amending the treaty establishing the European Economic Community with a view to establishing the European Community, Maastricht. 7 February 1992, Official Journal of the European Communities (OJEC), 29 July 1992, No C 191.

Galilei, G. (1932). Dialogo sopra i due massimi sistemi del mondo tolemaico e copernicano, Firenze, Per Giovanni Battista Landini.

Goudie, A. (2000). The human impact on the soil, In: The Human Impact on the Natural Environment (5th ed.), Massachussets, USA, Blackwell publishers, 160-201.

Ippolito, F. (1968). La natura e la storia. All'insegna del pesce d'oro, Milano,Vanni Scheiwiller.

Hooke, R.L. (1994). On the efficacy of humans as geomorphic agents, Gelogical Society of America Today, 4, 217-225.

Hugget, R.J. (1995). Geoecology: an evolutionary approach, London, Routledge.
John Paul II (1983). Discorso a un gruppo di scienziati e ricercatori in occasione del $350^{\circ}$ anniversario dell'opera di Galileo, 9 maggio 1983, Roma.

Jonas, H. (1990). Il principio responsabilità. Un'etica per la civiltà tecnologica, edited by P.P. Portinaro, Torino, Einaudi.

Keller, E.A., R.M. Blodgett and J.J. Clague (2008). Natural Hazards: Earth's Processes as Hazards, Disasters, and Catastrophes, New Yersey, USA, Pearson Education, Inc., Upper Sandle River, 15-26.

Lovelock, J. (1979). Gaia. A New Look at Life on Earth, Oxford University, $185 \mathrm{pp}$.

Maslin, M. (2004). Il nostro punto di vista determina il futuro, In: Global Warming. A Very Short Introduction, Paperback, Torino, Codice editor, 43-50 (in Italian).

Munn, R.E. (1996). Global chance: both scientific and a political issue, In: Policy Making in an Area of Gobal Environmental Change, edited by R.E. Munn, J.W. La Rivières and N. van Lookeren Campagne, Dordrecht, Kluwer Academic.

Nemec, V. (1991). Technical and ethical problems with computerized modelling of exploitation in open pits, Mining Pr`íbram Symposium, Czech Republic, vol. 4, 99-104.

Panizza, M., ed. (2005). Manuale di Geomorfologia Applicata, Milano, Franco Angeli, 15-30.

Praturlon, A. (2004). L'etica e l'integrità dell'habitat naturale risvolti etici del pensiero geologico, Rivista di Filosofia, 5, Roma.

Reed, L.A. (1980). Suspended-sediment discharge in five streams near Harringsburg, Pennsylvania, before, during and after highway construction, U.S. Geological Survey Water Supply Paper, 2072.

Spence, W., R.B. Herrmann, A.C. Johnston and G. Reagor (1993). Response to Iben Browning's prediction of 1990 New Madrid, Missouri, earthquake, U.S. Geological Survey Circular 1083.

Stenseen, N. (1669). De solido intra solidum naturaliter contento dissertationis prodromus, Firenze, ex Typographia sub signo Stellae.

United Nation (1987). Report of the World Commission on Environment and Development: Our Common Future, Brudtland Commission, 20 March 1987, Oslo, Norway. United Nation (1992). United Nations Conference on Environment and Development, 3-14 June, 1992, Rio de Janeiro, Brazil.

${ }^{\star}$ Corresponding author: Marco Giardino,

Università degli Studi di Torino, Dipartimento di Scienze della Terra, Torino, Italy; e-mail: marco.giardino@unito.it

(C) 2012 by the Istituto Nazionale di Geofisica e Vulcanologia. All rights reserved. 